\title{
Rzadko spotykane znaleziska u pacjenta z urazem wielonarządowym wymagającym pilnej laparotomii. Opis przypadku
}

\section{Rare and unexpected findings in a multitraumatized patient requiring emergency laparotomy. A case report}

\author{
Andrzej Żyluk ${ }^{\bowtie}$, Zbigniew Szlosser \\ Pomorski Uniwersytet Medyczny w Szczecinie, Klinika Chirurgii Ogólnej i Chirurgii Ręki, ul. Unii Lubelskiej 1, 71-252 Szczecin \\ $\triangle$ azyluk@hotmail.com
}

\begin{abstract}
Multitraumatic injuries are common in an era of widespread motoring. Abdominal trauma is linked with $30-40 \%$ of these injuries. Intraabdominal bleeding caused by ruptured abdominal viscera: liver, spleen or small bowel mesentery is potentially life-threatening and, in most cases, requires immediate surgical intervention.

The paper reports the case of a patient following multitrauma who was operated on in an emergency due to abdominal haem orrhage. During the laparotomy, apart from lesions causing
\end{abstract}

bleeding (laceration of the mesentery and small bowel perforation), two unexpected, uncommon lesions were found: a healthy Meckel diverticulum and haematoma in the mesentery of the appendix.

The rules of diagnostics and management in typical abdominal injuries are discussed, with special attention to some rare and atypical pathologies found during the operation.

Keywords: multitrauma; intraabdominal bleeding; Meckel diverticulum; vermiform appendix.

\begin{abstract}
ABSTRAKT
Urazy wielonarządowe są częste w dobie powszechniej motoryzacji, a obrażenia brzucha występują u ok. 30-40\% takich przypadków. Krwawienie do jamy otrzewnowej z pękniętych narządów wewnętrznych: śledziony, wątroby i krezki jelita cienkiego stanowi potencjalne zagrożenie życia i - w większości przypadków - wymaga pilnej interwencji chirurgicznej.

W pracy przedstawiono przypadek pacjenta z urazem wielonarządowym, u którego w trakcie laparotomii z powodu krwawienia wewnątrzbrzusznego, poza uszkodzeniami struktur
\end{abstract}

będących źródłem krwawienia (rozerwanie krezki i przedziurawienie jelita cienkiego), stwierdzono inne, rzadko spotykane patologie - zdrowy uchyłek Meckela i stłuczenie krezeczki wyrostka robaczkowego.

Omówiono zasady diagnostyki i leczenia typowych obrażeń w obrębie jamy brzusznej, a także postępowania w przypadku rzadkich i nietypowych patologii stwierdzonych w czasie operacji.

Słowa kluczowe: uraz wielonarządowy; krwawienie wewnątrzbrzuszne; uchyłek Meckela; wyrostek robaczkowy.

\section{WSTĘP}

Obrażenia wielonarządowe są stosunkowo częste w dobie powszechnej motoryzacji. Definiuje się je jako urazy dwóch lub więcej okolic ciała, przy czym przynajmniej jedno z tych obrażeń jest potencjalnie zagrażające życiu. Są to zatem poważne urazy, mogące mieć daleko idące konsekwencje dla zdrowia i życia chorych. Największym wczesnym zagrożeniem dla życia pacjenta z urazem wielonarządowym jest wstrząs krwotoczny, zwykle spowodowany krwawieniem wewnętrznym. Jest to najczęstsza przyczyna zgonów w czasie pierwszych 24 godz. po przywiezieniu chorych do szpitala [1]. Niekoniecznie musi być to masywny krwotok, np. z dużego naczynia brzusznego czy rozerwanej wątroby. Mniejsze krwawienia: z pękniętej śledziony, złamanych wielu żeber, złamanej miednicy czy kości udowej sumują się, wywołując ciężki wstrząs krwotoczny, który może spowodować zgon. Dlatego w postępowaniu z takimi chorymi istotne jest możliwie szybkie opanowanie krwawienia w jamie brzusznej. Z kilkuletniej praktyki autorów w leczeniu urazów wielonarządowych wynika, że najczęstsze przyczyny krwawienia wewnątrzbrzusznego to pęknięcie śledziony, krezki jelita cienkiego i wątroby.

W pracy przedstawiono przypadek pacjenta z urazem wielonarządowym, u którego w trakcie laparotomii z powodu krwawienia wewnątrzbrzusznego, poza uszkodzeniami struktur będących źródłem krwawienia, stwierdzono inne, rzadko spotykane patologie - uchyłek Meckela i stłuczenie krezeczki wyrostka robaczkowego.

\section{OPIS PRZYPADKU}

27-letni mężczyzna, kierowca samochodu osobowego, został przywieziony do Szpitalnego Oddziału Ratunkowego z miejsca 
wypadku. W wyniku utraty panowania nad pojazdem doszło do zderzenia z drzewem. Podczas przyjęcia pacjent był w stanie dość dobrym, przytomny, stabilny krążeniowo i oddechowo (własny oddech, RR 110/70), skarżył się na ból brzucha, lewej strony klatki piersiowej i lewego obojczyka. W czasie badania brzuch był napięty, bolesny, z zaznaczonymi objawami otrzewnowymi. Osłuchiwaniem klatki piersiowej stwierdzono symetryczny szmer pęcherzykowy. Pacjenta zacewnikowano, uzyskując wypływ czystego moczu. W wykonanym badaniu tomografii komputerowej (TK) w trybie urazu wielonarządowego stwierdzono:

- obecność krwi w jamie brzusznej bez lokalizacji źródła krwawienia (zarówno wątroba, jak i śledziona nie wykazywały uszkodzeń) - rycina 1 ,

- obecność krwiaka przestrzeni zaotrzewnowej w okolicy prawej nerki (ryc. 2),

- złamania III-VI żebra po stronie lewej,

- stłuczenie lewego płuca,

- złamanie lewego obojczyka.

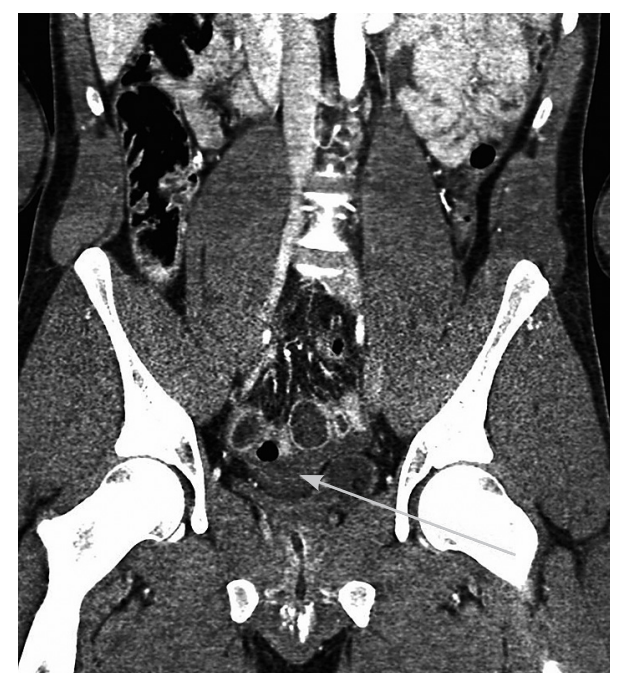

RYCINA 1. Obraz tomografii komputerowej wykazujący obecność krwi w zatoce Douglasa (oznaczona strzałką)

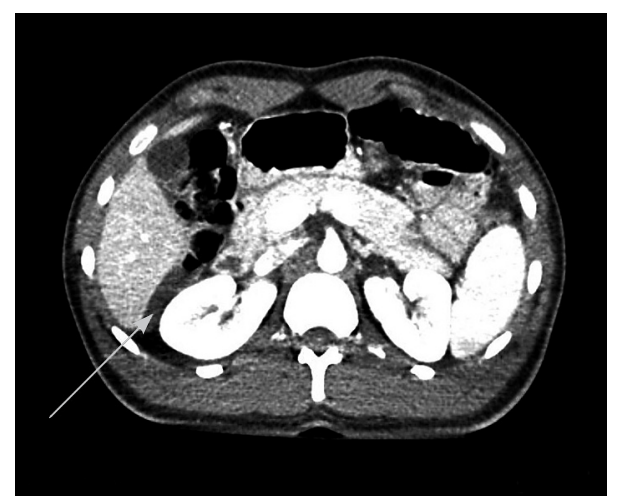

RYCINA 2. Obraz tomografii komputerowej wykazujący obecność krwiaka zaotrzewnowego w okolicy prawej nerki

Uwzględniając obraz radiologiczny i stan kliniczny wskazujący na obrażenia narządów wewnętrzny w jamie brzusznej, zdecydowano się na operację w trybie pilnym.

\section{SPOSTRZEŻENIA ŚRÓDOPERACYJNE}

Jamę brzuszną otwarto cięciem pośrodkowym w nadbrzuszu, przechodzącym do połowy podbrzusza, z ominięciem pępka. W jamie otrzewnowej stwierdzono obecność świeżej krwi, której odessano ok. 700 mL. W pierwszej kolejności skontrolowano narządy miąższowe: wątrobę i śledzionę, nie stwierdzając ich uszkodzenia. Następnie skontrolowano jelita, rozpoczynając od więzadła Treiza.

Mniej więcej w połowie długości jelita cienkiego uwidoczniono rozerwanie jego krezki na przestrzeni ok. $10 \mathrm{~cm}$, ale bez aktywnego krwawienia (ryc. 3). Około $10 \mathrm{~cm}$ za tym miejscem uwidoczniono niezmieniony uchyłek Meckela (ryc. 4). W dalszej części jelita krętego uwidoczniono jego urazowe rozerwanie z kilkucentymetrowym obszarem stłuczenia (ryc. 5). Podnosząc kątnicę, stwierdzono stłuczenie krezeczki wyrostka robaczkowego z krwiakiem (ryc. 6). Kontrolując jelito grube, zauważono stłuczenie esicy z rozerwaniem jej krezki i pęknięciem błony surowiczej na powierzchni ok. połowy obwodu (część esicy była jakby „odarta” z surowicówki). W prawym śródbrzuszu uwidoczniono krwiak przestrzeni zaotrzewnowej.

Po identyfikacji wymienionych wcześniej uszkodzeń, przystąpiono do ich naprawy. Ze względu na obszar stłuczenia jelita krętego wokół miejsca jego rozerwania wykonano wycięcie ok. 15 cm fragmentu jelita i zespolenie kikutów koniec do końca szwem jednowarstwowym. Zszyto rozerwaną krezkę jelita czczego. Z uwagi na stłuczenie krezeczki wyrostka robaczkowego i możliwość jego późniejszego niedokrwienia lub zapalenia, wykonano appendektomię (ryc. 7). Pozostawiono niewykazujący zmian uchyłek Meckela. Zszyto rozerwaną krezkę esicy i pozostawiono bez zaopatrzenia pęknięcie jej surowicówki.

Po wykonaniu kontroli hemostazy i ostatecznej kontroli narządów jamę brzuszną zamknięto, pozostawiając dren w okolicy zatoki Douglasa.

\section{PRZEBIEG POOPERACYJNY}

Kontrolna morfologia po operacji wykazała anemizację wymagającą przetoczenia 2 j. k.cz. Przebieg pooperacyjny był powikłany stosunkowo długim, 4-5-dniowym okresem niedrożności

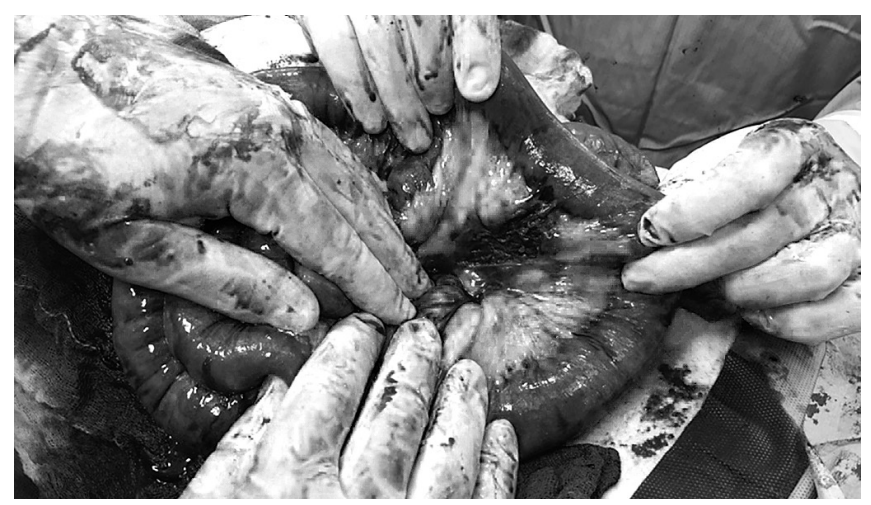

RYCINA 3. Rozerwanie krezki jelita cienkiego 


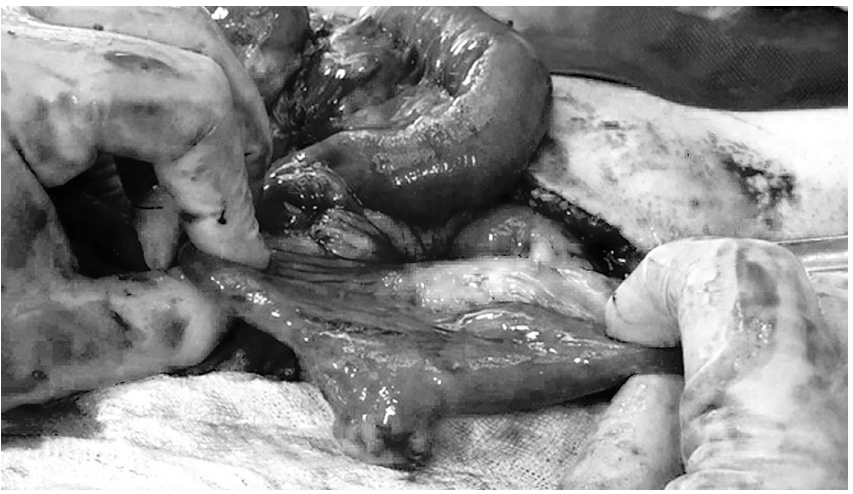

RYCINA 4. Niezmieniony uchyłek Meckela

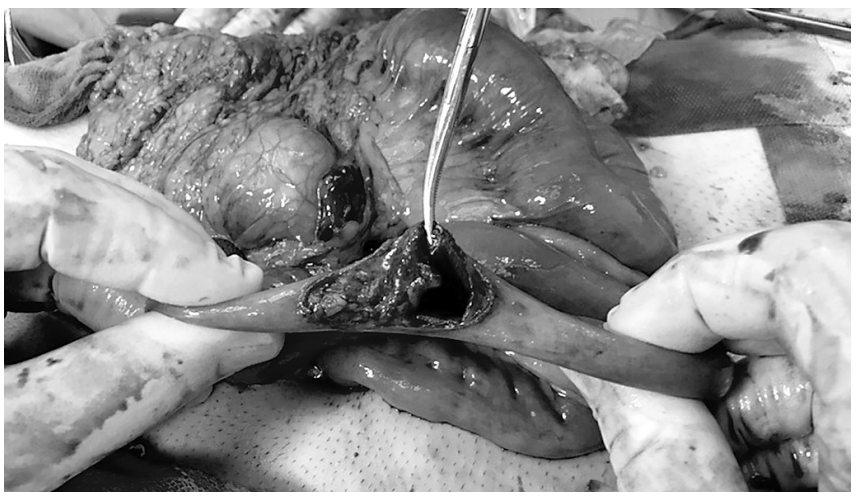

RYCINA 5. Rozerwane jelito kręte

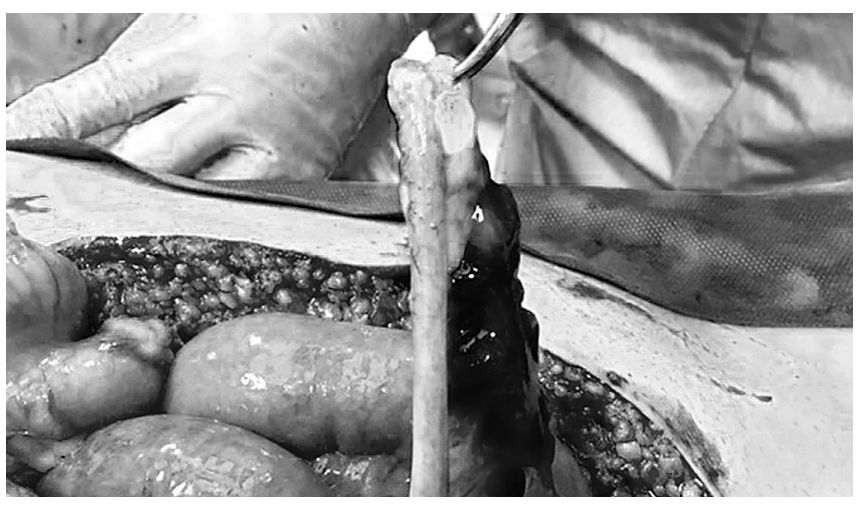

RYCINA 6. Wyrostek robaczkowy z krwiakiem w krezeczce

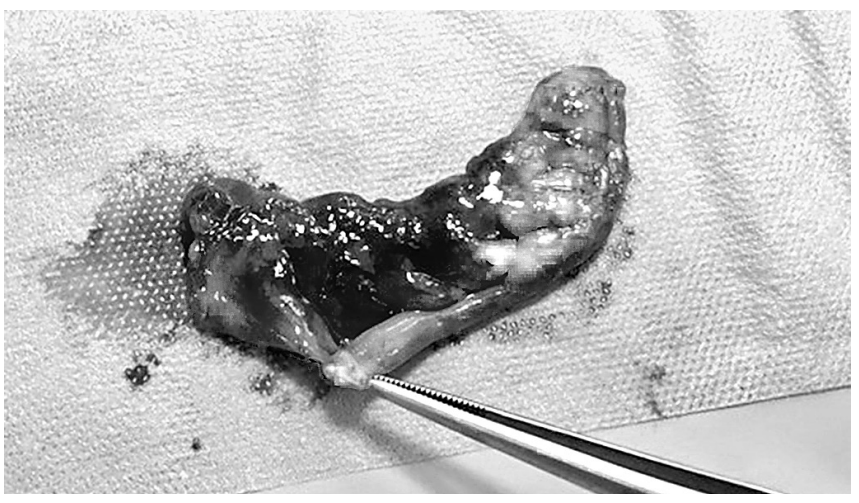

RYCINA 7. Wycięty wyrostek robaczkowy z krwiakiem krezeczki porażennej jelit, co objawiało się bólem i wzdęciem brzucha oraz wymiotami. W 3. dobie założono sondę do żołądka i odessano ok. 1,5 L treści zalegającej. Przez następne 2 dni z sondy ewakuowało się 1,5-2 L takiej treści na dobę. Pomimo sondy pacjent miał także tendencję do wymiotów, nie oddawał gazów, a osłuchiwanie brzucha wykazywało brak szmerów perystaltycznych. Z drenu ewakuowało się ok. 200 mL treści surowiczo krwistej na dobę. Taki stan kliniczny wzbudzał podejrzenie zapalenia otrzewnej w wyniku rozejścia się zespolenia jelitowego lub perforacji stłuczonej esicy. W 4. dobie wykonano badanie USG, które nie wykazało obecności zbiorników płynu w jamie brzusznej. Od 5. doby pooperacyjnej stan chorego stopniowo się poprawiał, ustąpił ból brzucha i wróciła perystaltyka. W 6. dobie rozpoczęto pojenie, a potem odżywiane doustne. Kontrolne RTG klatki piersiowej nie wykazało obecności odmy opłucnowej ani stłuczenia lewego płuca. Po 10 dniach od urazu i operacji, pacjenta w stanie dobrym, z zagojoną raną operacyjną, przekazano do Kliniki Ortopedii w celu operacji złamanego obojczyka.

\section{OMÓWIENIE}

Chory z urazem wielonarządowym jest w stanie potencjalnego zagrożenia życia i dlatego postępowanie z nim powinno być szybkie i zdecydowane. Największe zagrożenie bezpośrednio po wypadku stanowi krwawienie i dlatego odpowiedź na pytania, „czy i skąd chory krwawi”, ma zasadnicze znaczenie w planowaniu postępowania diagnostycznego i leczniczego [1]. Najlepszym badaniem do oceny obrażeń pacjenta z urazem wielonarządowym jest TK w trybie „politraumy”. W jamie brzusznej umożliwia wykrycie:

- obecności krwi w jamie otrzewnowej i orientacyjne określenie jej ilości,

- obecności powietrza, co świadczy o pęknięciu przewodu pokarmowego - żołądka lub jelita,

- uszkodzenia narządów miąższowych: wątroby, śledziony i trzustki,

- krwiaków zaotrzewnowych wskutek np. złamania kości miednicy,

- uszkodzenia układu moczowego: nerek, pęcherza i ewentualnie wynaczynienia moczu.

Tomografia komputerowa wykonana z opcją naczyniową pokazuje stan dużych naczyń - aorty brzusznej i jej głównych odnóg: tętnicy krezkowej górnej i pnia trzewnego, a także żyły głównej dolnej i wrotnej.

Należy stwierdzić, że dokładność oceny obrażeń jamy brzusznej w TK nie jest pewna na 100\%, co oznacza, że niektóre urazy mogą nie być widoczne, np. pęknięcia narządów miąższowych przebiegające bez większego wynaczynienia krwi, a także rozerwanie jelita cienkiego i jego krezki, jak to było w omawianym przypadku. Takie uszkodzenia mogą uwidocznić się później, w badaniu kontrolnym. Na rycinach 8 i 9 przedstawiono rozległe rozerwanie krezki jelita cienkiego, wymagające resekcji jego fragmentu u innego pacjenta $\mathrm{z}$ urazem wielonarządowym, u którego w TK opisano tylko obecność niewielkiej objętości krwi w jamie brzusznej. Ze względu 
na taki obraz radiologiczny i cechy wstrząsu krwotocznego pacjenta operowano $\mathrm{w}$ trybie pilnym.

Przedstawiony w pracy przypadek jest przykładem standardowego postępowania z pacjentem po urazie wielonarządowym (brzucha i klatki piersiowej), u którego stwierdzono radiologiczne objawy krwawienia wewnątrzbrzusznego. Taki pacjent zwykle wymaga laparotomii, chociaż decyzja o operacji zależy w pewnym stopniu od stanu ogólnego i obecności innych obrażeń.

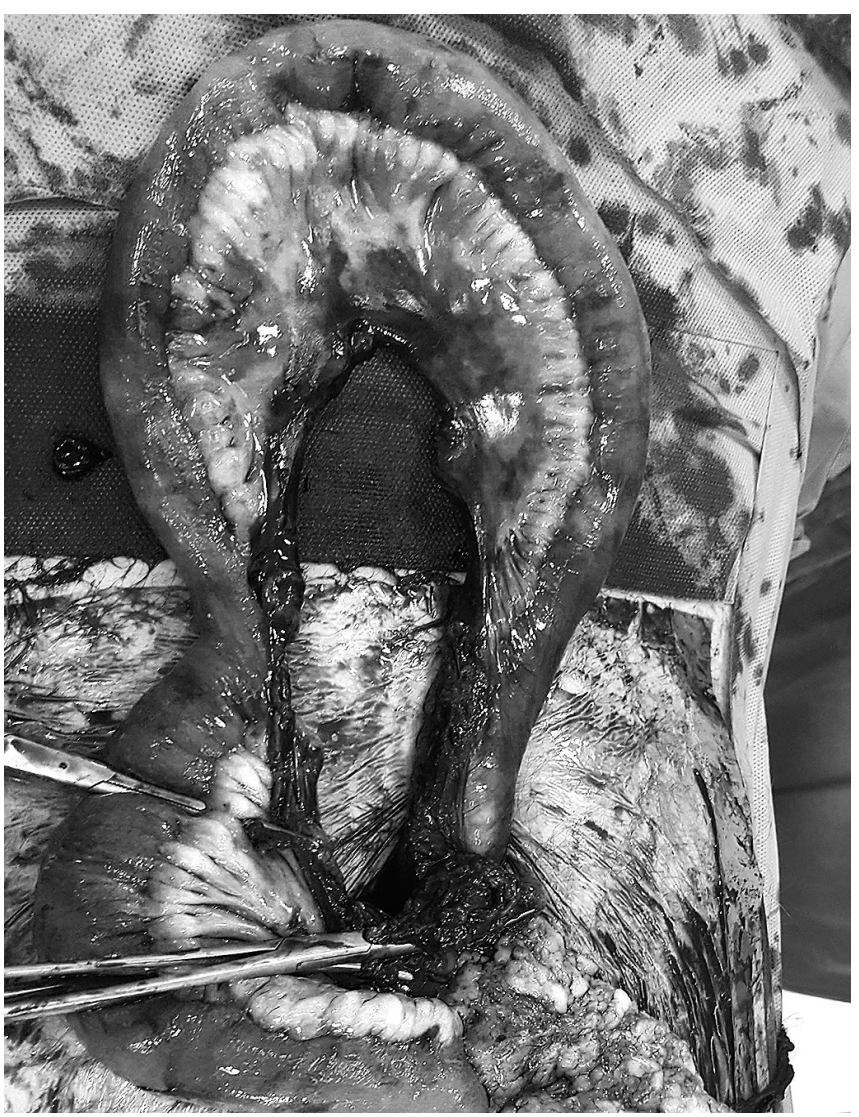

RYCINA 8. Rozległe rozerwanie krezki jelita cienkiego wraz z niedokrwieniem jelita

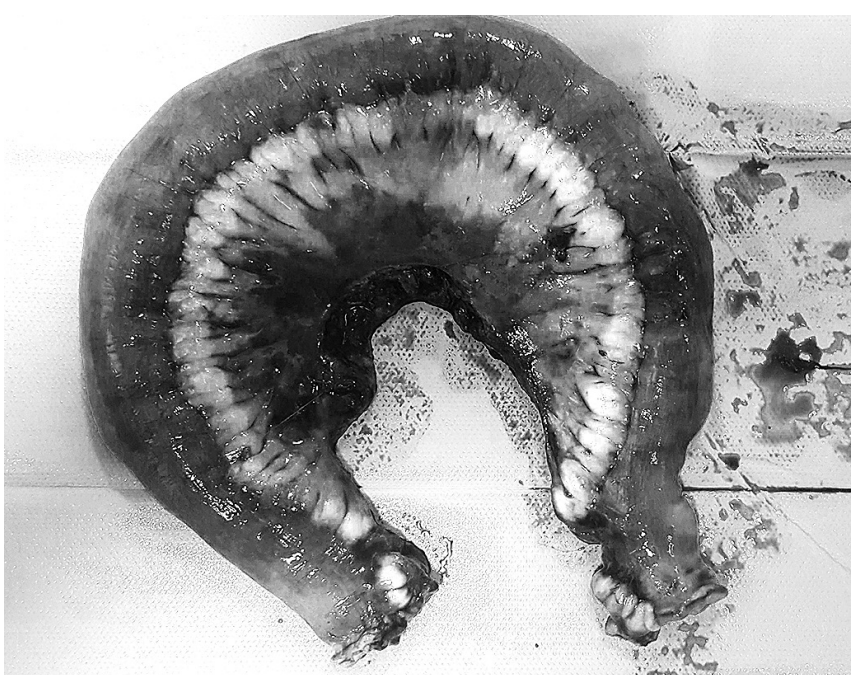

RYCINA 9. Wycięty fragment jelita cienkiego
Jeżeli pacjent jest w stanie stabilnym, przy tomny i ma dobre ciśnienie krwi, a inne obrażenia nie wymagają leczenia operacyjnego, można zdecydować się na postępowanie zachowawcze: monitorowanie parametrów życiowych, obserwacja brzucha i kontrola morfologii. Jeśli w ciągu 12-24 godz. stan pozostanie stabilny i nie wystąpi anemizacja, a badanie brzucha nie wykaże niepokojących objawów (np. otrzewnowych, wzdęcia, braku perystaltyki), to takie postępowanie można kontynuować.

Jeżeli jednak pacjent prezentuje objawy wstrząsu krwotocznego (niskie ciśnienie krwi), niepokojące objawy brzuszne lub wymaga innej operacji ze względu na towarzyszące obrażenie (np. złamania miednicy, kręgosłupa lub kończyn), to rozsądniejszym rozwiązaniem będzie laparotomia, uzyskanie hemostazy wewnątrzbrzusznej i naprawa ewentualnych uszkodzeń narządów wewnętrznych. Operacja ortopedyczna wiąże się z przekładaniem pacjenta na stół operacyjny, często odwracaniem na brzuch, co może nasilić krwawienie i spowodować spadek ciśnienia przed- lub w trakcie operacji kostnej. Z takimi sytuacjami autorzy spotkali się w swojej praktyce.

W omawianym przypadku decyzja o pilnej laparotomii była podyktowana objawami klinicznymi podrażnienia otrzewnej i radiologicznymi - krwawienia wewnątrzbrzusznego. Cześć ze stwierdzonych śródoperacyjnie obrażeń była typowa:

- rozerwanie krezki jelita cienkiego i krezki esicy powodujące umiarkowane krwawienie,

- pęknięcie jelita cienkiego,

- uszkodzenie surowicówki esicy.

Nietypowe i wyjątkowe było natomiast stłuczenie krezeczki wyrostka robaczkowego z jej krwiakiem i obecność uchyłka Meckla. Postępowanie w przypadkach większości takich uszkodzeń jest także standardowe:

- rozerwaną krezkę jelita powinno się zszyć,

- rozerwane jelito trzeba zszyć, ale kiedy okolica zranienia jest stłuczona i są wątpliwości co do ukrwienia, lepiej jest resekować odcinek jelita i zespolić dobrze ukrwione końce.

Postępowanie z uszkodzeniami surowicówki jelit nie jest już takie oczywiste. Zdarzają się one stosunkowo często w trakcie innych operacji, np. z powodu niedrożności jelit lub w trakcie ich uwalniania ze zrostów. Są zwolennicy zszywania naddartej surowicówki, inni radzą pozostawiać je bez prób naprawiania. Obszary, w których przez ubytek uwypukla się śluzówka (ale nie jest przerwana), lepiej zszyć szwem ciągłym, obejmującym błonę surowiczą i mięśniową [2].

Postępowanie z przypadkowo znalezionym, niezmienionym uchyłkiem Meckela jest przedmiotem kontrowersji. Najczęściej jest on odnajdywany przy wykonywaniu appendektomii, ponieważ większość chirurgów po wycięciu wyrostka robaczkowego sprawdza końcowy odcinek jelita cienkiego, gdzie zwykle się go odnajduje. W takiej sytuacji zaleca się wycięcie niezmienionego uchyłka Meckela, aby uniknąć ewentualnych przyszłych kłopotów, np. zapalenia, przedziurawienia czy krwawienia. Postępuje się z nim tak samo jak z niezmienionym wyrostkiem robaczkowym w czasie operacji z powodu podejrzenia jego zapalenia. Warto jednak pamiętać, że większość powikłań uchyłka Meckela występuje w okresie dziecięcym 


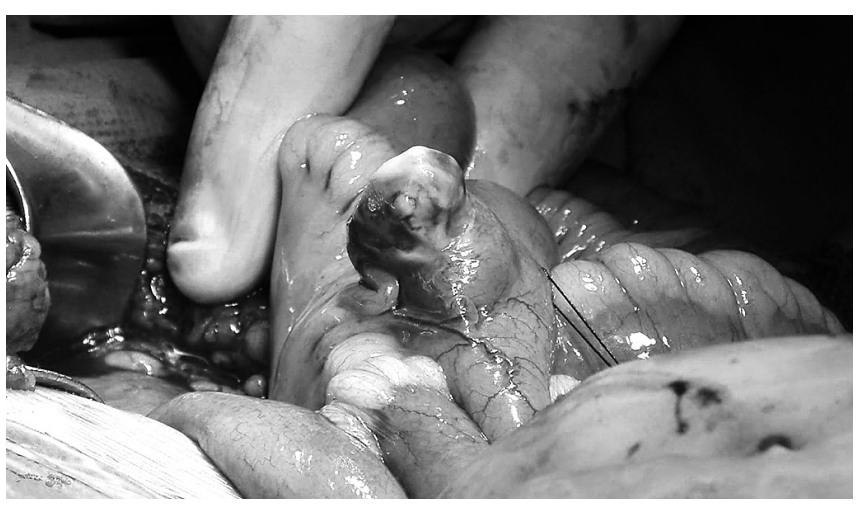

RYCINA 10. Zmieniony zapalnie uchyłek Meckela

i młodzieńczym, a u dorosłych tylko wyjątkowo. W swojej praktyce starszy autor pracy spotkał się tylko raz ze zmienionym zapalnie uchyłkiem Meckela u 30-letniej pacjentki operowanej z powodu bólu brzucha o niejasnej etiologii zlokalizowanego w lewym śródbrzuszu, któremu towarzyszyło podwyższenie biochemicznych parametrów stanu zapalnego (ryc. 10). Jednak wycięcie uchyłka Meckela, szczególnie dużego, o szerokiej podstawie, nie jest takie proste jak appendektomia i w niektórych okolicznościach może być ryzykowne. Takie sytuacje to:

- miejscowe lub rozlane zapalenie otrzewnej (np. w przypadku zgorzelinowego, perforowanego wyrostka robaczkowego),

- obrażenia innych narządów jamy brzusznej u pacjenta $\mathrm{z}$ urazem wielonarządowym,

- duża operacja brzuszna z powodów onkologicznych,

- podeszły wiek.

W takich okolicznościach lepiej nie wycinać uchyłka, tylko odnotować jego obecność w protokole operacyjnym i karcie informacyjnej pacjenta. Także uchyłki płaskie, o szerokiej podstawie i cienkiej, wyglądającej na „normalną” ścianie, lepiej pozostawić, gdyż wyjątkowo rzadko dają wspomniane wcześniej powikłania. Obecnie jest coraz więcej zwolenników zostawiana zdrowego uchyłka Meckela, nawet przy appendektomii $[3,4]$. Wycięcie uchyłka zaleca się w przypadku wystąpienia:

- wąskiej szyi uchyłka, co stwarza ryzyko zatkania przez resztki pokarmowe,

- pogrubiałej ściany z wyczuwalnymi grudkami w środku, co sugeruje obecność nieprawidłowej błony śluzowej,

- połączenia szczytu uchyłka z pępkiem pasmem łącznotkankowym (względne wskazanie) [5, 6].

Stłuczenie krezeczki wyrostka robaczkowego wraz z jego krwiakiem nie było dotychczas opisywane, być może ze względu na marginalne znaczenie takiego urazu. Jednak wycięcie wyrostka robaczkowego w takiej sytuacji wydaje się postępowaniem racjonalnym, ponieważ pozostawienie go mogło potencjalnie zagrażać niedokrwieniem i rozwojem zapalenia. W piśmiennictwie autorzy znaleźli tylko opis przypadku amputacji połowy wyrostka robaczkowego u pacjenta po tępym urazie brzucha spowodowanym pasami bezpieczeństwa [7].

\section{PIŚMIENNICTWO}

1. Żyluk A. Obrażenia wielonarządowe. In: Żyluk A, editor. Zarys chirurgii. Podręcznik dla studentów i lekarzy w trakcie specjalizacji. Warszawa: Medipage; 2016. p. 420-8.

2. Schein M. Niedrożność jelita cienkiego. In: Schein M, Rogers PN, Assalia A, editors. Zdrowy rozsądek w chirurgii ostrego brzucha. Warszawa: Medmedia; 2013. p. 193-208.

3. Górecki W. Nagłe schorzenia brzuszne u niemowląt i dzieci. Uchyłek Meckela. In: Schein M, Rogers PN, Assalia A, editors. Zdrowy rozsądek w chirurgii ostrego brzucha. Warszawa: Medmedia; 2013.p. 334.

4. Ruscher KA, Fisher JN, Hughes CD, Neff S, Lerer TJ, Hight DW, et al. National trends in the surgical management of Meckel's diverticulum. J Pediatr Surg 2011;46:893-6.

5. Hall JF, Stein SL. Unexpected intra-operative findings. Surg Clin North Am 2013;93:45-59.

6. Dunlop MG. Jelito i wyrostek robaczkowy. Uchyłek Meckela. In: Garden OJ, Bradbury AW, Forsythe JL, Parks RW, editors. Chirurgia. Podręcznik dla studentów. Wrocław: Elsevier, Urban \& Partner; 2009. p. 341.

7. Go SJ, Sul YH, Ye JB, Kim JS. Appendiceal transection associated with seat belt restraint. Ann Surg Treat Res 2016;91(2):93-5.

\section{KOMENTARZ}

Praca w zwięzły sposób przedstawia sposób postępowania z chorym z urazem wielonarządowym, ze szczególnym uwzględnieniem leczenia chirurgicznego obrażeń wewnątrzbrzusznych. Za wyróżniające opisywany przypadek Autorzy uznali stwierdzenie podczas laparotomii stłuczenie z krwiakiem krezeczki wyrostka robaczkowego oraz obecność uchyłka Meckela o szerokiej podstawie. Autorzy słusznie napisali w Omówieniu, że „stłuczenie krezeczki wyrostka nie było dotychczas opisywane, być może ze względu na marginalne znaczenie tego urazu". Postępowanie operatorów (usuniecie wyrostka) należy uznać za jak najbardziej racjonalne, natomiast pozostawienie go należałoby uznać za błąd, który mógłby skutkować powstaniem ropnia na tle krwiaka krezeczki czy zapalenia wyrostka robaczkowego.

Co do postępowania z uchyłkiem Meckela o szerokiej podstawie, to i w tym przypadku postępowanie wydaje się właściwe, choć jego resekcja za pomocą staplera liniowego nie zwiększyłaby prawdopodobnie ryzyka powikłań pooperacyjnych. Autorzy słusznie piszą, że tego typu uchyłki rzadko są przyczyna powikłań, choć w tym miejscu w Omówieniu należałoby może nieco szerzej opisać fakt stosunkowo często występującej w uchyłkach tkanki ektopowej. Nie jest też prawdą, że takie uchyłki o szerokiej podstawie w ogóle nie mogą być przyczyną powikłań (o czym Autorzy także piszą).

Autor niniejszego komentarza operował przed laty pacjentkę z objawami niedrożności jelita cienkiego spowodowanego zalegającymi resztkami pokarmowymi w takim właśnie uchyłku, który stał się „kieszonką” gromadzącą resztki błonnika po jednorazowym spożyciu znacznej objętości warzyw i owoców Niedrożność jelit spowodowana zaleganiem treści pokarmowej w uchyłku Meckela. Pol Przegl Chir 2006;75(4):414-6. Może warto byłoby powołać się w omówieniu na ten przypadek?

dr hab. n. med., prof. UM Jacek Karoń 